\title{
Generating Factors of Success and Failure of Companies: Empirical Research on Turkish Companies
}

\author{
Thaer Alasaad, Mehmet şahin gök
}

\begin{abstract}
In the economic field, business development is crucial for the socioeconomic development. On the one hand, the creation of companies can be an effective solution of the unemployment. On the other hand, business development is an essential factor of economic growth. Thus, the development of a country is correlated with its business development. However, business results are not always guaranteed. For this reason, controlling a number of factors related to results is an absolute necessity. Our research aims at studying a set of elements contributing to the results of the success and failure of Turkish companies. For this purpose, we considered a sample of 46 companies, which is subdivided into two sub-samples, the first represents the "Successful companies "; this category represents $74 \%$ of the total sample. The second represents the remaining $26 \%$ formed the "Failure companies". Empirical results highlight the importance of factors related to; the Business plan, the innovation, the marketing strategy, and the human resources. However, ignoring these factors lead to the business failure. Therefore, the prediction of success or failure factors will deliver key information to decision-makers on the mistakes to be avoided and the precautions to be taken.
\end{abstract}

Index Terms: Success, Failure, Business plan, Innovation, Marketing, Human Research, Turkish Companies.

\section{INTRODUCTION}

Since its popularization in the 80 s by Porter, the concept of success factor raises a certain interest. The research of the factors of success in an industry and / or a given company is considered as a stage of the strategic analysis. A number of empirical studies were undertaken in strategy and in entrepreneurship. By studying the factors of success, also highlighted the causes of failure of the companies. Nevertheless, in spite of researchers, the explanation of factors and causes of failure remains unclear or hardly understandable. companies succeed? Or why is it that others fail? The main question of the research was therefore formulated as follows:

What opposes and discriminates the companies that succeeded of those which failed? In other word, which are the true determinants of the competitiveness of the companies in Turkey?

The answer to the main question we generate a set of objectives to be reached.

Our first objective is to describe and analyze the two
Two problematics motivated our research. Why do some

groups of successful and failed companies in order to highlight the following characteristics: Strategic Vision \& Business plan, Innovation, Marketing strategy and Human resources.

A second major objective is to compare the characteristics of the two groups (undertaken with success and failure) in order to clearly and distinctly differentiate the resulting differences.

This study has several interests. Firstly, the prediction of success or failure will deliver key information to decision-makers on the errors to avoid and the precautions to be taken. Thus, from an economical point of view, the use of the results will make it possible to inform politicians, investors and others about the excellence award. On the social front, the path to success can also be seen as an effective solution of the unemployment in the region.

The remain of this paper is organized as follow; the next section reviews several studies in this domain. Section 3 presents theoretical framework, which analyses of the notion of success and failure of companies. The survey results were presented in section 4, which include a business recommendation section. Finally, a conclusion will be provided.

\section{LITERATURE REVIEW}

This section puts the study in context and provides a review of the literature on the subject. The different elements of the research are presented and defined in order to better understand the problematic.

The literature review begins with a clarification of the notion of success, followed by identification and presentation of the most relevant criteria or performance indicators. The notion of success has been the subject of several researches in different contexts and domains (success of new products, success in the field of information systems ...). However, project management remains the discipline in which success has been most debated.

In the literature, Baker, Murphy and Fisher (1988) suggested that a project is considered as succesfull when it achieves the three objectives: time, cost and performance, satisfied the customer and satisfied the project team According to Pinto and Sievin (1986) a project is considered as succesfull when it is technically valid, valid for the organization and improves efficiency of organization.

Revised Version Manuscript Received on August 19, 2019.

Thaer Alasaad, Gebze teknik üniversitesi , Turkey.

(Email: thaeralassad48@gmail.com)

Mehmet şahin gök, Gebze teknik üniversitesi , Turkey.

(Email: sahingok@gtu.edu.tr) 
Ashley, Lurie and laselskis (1987) affirmed that a project is a success if it records the results expected or better than expected in terms of cost, time, quality, safety and satisfaction of participants. For De Wit (1988), A project is a total success if it presents a high satisfaction for key people within the organization and key people within the project team users and clients of the project. Nguyen, Ogunlana and Lan (2004) suggested that a project is recognized as successful if it is completed in time, the allocated budget is in agreement with the specificities and the satisfaction of the stakeholders.

One of the most difficult tasks in evaluating performance is to define the parameters in which the success will be measured. Since the notion of success is subjective and varies from one person to another, the determination of criteria for measuring it becomes confused. The same project can be seen as successful for one party and considered as a failure for another (De Wit (1998). Moreover, Baker, Murphy and Fisher (1988) talk about the perceived success. It is therefore derisory to claim to identify an exhaustive list of criteria or indicators that measure the success of a project or a product. In this context, Achanga et al (2006); Nguyen et al (2004); Fryer et al (2007); Cooper (2003); Mattesich et al (2001); Morrison et al (2004), McNeil et al. (1986); Préfontaine et al (2002); Pinto and Sievin (1986) and Zwikael and Globerson (2006) provided the factors of success related to project / product such as; the clear identification of project purpose and objectives by all members, good project planning, availability of financial resources and the novelty of the product. However, Morrison et al (2004); Préfontaine et al (2002); Mattesich et al (2001); Fryer et al (2007); Nguyen et al (2004) and Zwikael et Globerson (2006) noted the factors mentioned the level of involvement of the partners in the project, the commitment of members in the pursuit of the objectives of the project, the climate of trust between members of the team and the communication. Finally, Préfontaine et al (2001) : Mattesich et al (2001), Bissonnette (1996), and Reed (1997) studied the factors related to the political, economic and social environment. To sum up, previous researches highlighted the importance of some factors in determining the success or fail of firms. However, none of them mentioned the failure factors. In our research, we studied both the success and the failure factors in relations with suppliers, financial management, marketing strategy and the human resources. This study is conducted on Turkish companies. Moreover; we provide a business recommendation, which can be a reference for future entrepreneurs, include the success factors to follow and the failure factors to avoid.

\section{Success and failure factors identification}

We have long wondered why some firms are more apt to succeed thanothers. The researches of entrepreneurship specialists allow today to give some answers to this question. Thus, the purpose of this section is, on the one hand, to enlighten the reader on the notion of success and failure; and on the other hand, to identify the characteristics of successful and failure companies. In this perspective, we analyse firstly, the concepts of success and failure in business and what their corollaries contain. It is one of the most important stages of related to relationships between project members. They

our research. Second, a general view of the exemplary companies has been studied.

\section{1. Analysis of the notion of success and successful} companies

It has frequently asked why some enterprises are more able to succeed compared to others. Now, the research of strategists and entrepreneurship specialists allows us to give some answers to this question.

\section{Factors of success}

Churchil and Lewis (1983) identified eight key success factors in SMEs. They divided these factors into two categories: those concerning the company and those that relate to the owners. Factors related to the business are:

- Financial resources: including cash and borrowing opportunities.

- Human resources: in terms of the number, competence and quality of staff, particularly at the level of management and functional departments.

- Management systems: in terms of the sophistication of information systems, planning and control.

- Competitive resources: including customer relations, market share, and relationships with suppliers, manufacturing and distribution processes, technology, reputation, are key determinants of the company's business and its market.

The factors inherent to owners are:

- The goals the owner has set for himself (or herself) and for his or her business.

- Operational skills of the owner in carrying out important tasks such as marketing, invention, production, and distribution management.

- The management capacity of the owner, his willingness to delegate to subordinates and his ability to manage their activities.

- The strategic skills of the owner that allow him to see beyond the present and adapt the strengths and weaknesses of his company to the goals he (she) has set.

\section{The successful company}

The successful company can be perceived differently according to each participant: investors (owners), creditors, customers and employees.

Investors and creditors are more interested in financial indicators. For investors, the objective is simple: the profitability of their investment. This indicator will then measure the success of the company.

If the company does not generate enough resources, it will not be able to pay its debts, and the creditors will perceive it as a failed company.

For customers, the company achieves success according to the goods and services it disposes, and by the way gives them the utility and the expected satisfaction. Success will be translated into a specific evaluation, taking into account factors considered important by clients. Responding to client concerns becomes an indicator of success: compliance with 
delivery deadlines, product or service quality, and the cost to pay.

Employees will evaluate success in proportion to their salaries.

\section{2. The concept of failure}

It is common to hear about business failure or Failure Company. The business failure is linked to a set of factors. Understanding this set of factors should help to prevent failure. Thus, in this section, we will present the concept of failure and the causes inherent in the failure

\section{2.1. The concept of failure}

Berryman (1982), failure is a multiple notion. He gives several definitions:

- Fails, a company whose profitability is insufficient: a company has failed if it does not receive a fixed rate of return for an adequate investments;

- Fail, companies that have ceased their activities and have officially declared bankruptcy; have caused losses to their creditors; have voluntarily shut down without fully fulfilling their obligations; have been involved in reorganizations; negotiated voluntary repayment agreements with their corporate creditors;

- Fails, companies affected by legal bankruptcy;

- Fails, companies that regularly makes losses and liquid to put an end to this situation.

Many authors assimilate Beryman's definitions to bankruptcy. Thus, Julien (1997) finds the significant differences in the failure rate according to the definition used. $\mathrm{He}$ argues that it is necessary to distinguish between failure and bankruptcy before making any conclusion.

Bankruptcy is a complete form of failure. For an entrepreneur, it is marked by a cessation of payment. While failure is a negative result of an attempt.

\subsection{The failure factors}

\section{The causes related to the entrepreneur}

\section{- Aspects related to the creation,}

$\checkmark$ Overestimating the idea: entrepreneurs tend to overestimate the viability of their project idea and do not take the precaution to evaluate it.

$\checkmark$ Insufficient maturity: Entrepreneurs in their haste, does not give time to the idea to be sufficiently mature; generally, they begin the initial steps of creation without ensuring the viability of the idea.

$\checkmark$ Lack of self-confidence: entrepreneurs lack confidence, hesitate in decision-making and poorly sell their idea.

$\checkmark$ Lack of creativity: many entrepreneurs are not imaginative and are not tempted by innovation.

$\checkmark$ Aspects related to the environment;

$\checkmark$ Family conflicts where several cases can arise: a conflict between the entrepreneur and a family member (company employee) can be settled at the expense of the company interest.

$\checkmark$ Family Opposition: This situation is very common among people who leave a stable job to start their own business. The family may also oppose a member's involvement in a traditional caste occupation.
Unfair competition from the State: this is reflected in the fact that the State produces the same good or service as companies.

\section{- $\quad$ Financial aspects}

Inadequate equity: the company often incurs considerable debt in order to make up the shortfall in equity. The profitability of the company is affected by the payment of significant interest.

$\checkmark$ Inefficient treasury management: few entrepreneurs use the treasury plan as a management tool.

$\checkmark$ Inadequate capital: companies with an unstable balance structure tend to borrow a short- term credit to cover capital shortfalls.

\section{- $\quad$ The causes related to the company}

Clifford and Cavanagh (1987)attribute the reasons for failure to three causes: strategy errors, financial mistakes, human mistakes.

\section{- $\quad$ Strategy errors}

The company considered as creative while there is a mutation. In addition, the company fails because it has not been able to change its management strategy. It is also fails because its market is very restricted. Failure is also linked to lack of innovation. The company does not change, does not adapt to the change of the environment;

\section{- Financial mistakes}

Companies fail because they finance poorly their development plans.

\section{- Human mistakes}

The failure is due to the lack of enthusiasm and cooperation. The entrepreneur simply loses interest in his business. Kombou (1999) identifies some causes related to the failure of large companies:

Non-technological control: companies use complex technologies that is difficult to control.

$\checkmark$ The lack of qualified managers: the lack of a managerial culture and inexperience areput forward as causes of company failure.

$\checkmark$ Insufficient of financial resource: the complex structure requires important financial resources. When these resources are not available, they evolve in a financial contrast and eventually disappear.

\section{SURVEY AND DATA ANALYSIS \& RESULTS}

What are the factors that make the most successful companies in Turkey special compared to the others? What they do in a different way? Does they own special potentials, which let them to in increase their profit and their market share? This present study attempts to response the mentioned questions by referring to the previous studies and then make a comparative study of the strategies applied by a sample of successful companies against fewer successful ones. In addition, this research studies the main factors, which explain 
why companies, which in the past have been successful, may have had trouble in their financial resources. This research is based on two studies. To determine the factors that distinguish successful companies from failure companies, a surveyl was conducted among 46 medium and small companies (or enterprises); (SMEs) in Istanbul. The questions asked focused on the business practices of the surveyed companies and the extent to which certain activities were conducted. In many cases, respondents needed to determine where their business was in relation to their major competitors (for example, regarding the practices of compensation of employees). We can also ask them about the performance of their business financial during the previous 3 years. With the aim to recognize the factors of success for all companies, we divided the respondents into 2 sets (two different samples). The group of "successful companies ", this category represents $(74 \%)$ of the total sample, ie 34 companies. The remaining $26 \%$ formed the "Failure companies" ie 12 companies. We then compared the two groups' responses to questions and we grouped most of the significant results together to formulate the success factors of general application.

The questions of our Survey are written following an analysis of pertinent economic and business publications and more than 20 in-depth interviews with professionals in business and entrepreneurs that allow us to better understand some of the main factors that lead to the success of a business

On the other hand, the survey of failure companies allows us to formulate the factors of failure to avoid. Previous studies have focused on the characteristics of leaders who have most often led companies to bankruptcy. The aim of our study was to recognize the main factors and events, which explain some financial difficulties - even temporary - of business. The results of our research are divided into 2 parts. The first presents factors analysis that can lead to either to the failure or to the success of the company, these factors are related to the business plan and vision, innovation, human resources and marketing strategy, in the second part of the recommendations and strategies to avoid these pitfalls, have been proposed.

\section{EMPIRICAL RESULTS \& INTERPRETATION}

\section{Strategic Vision \& Business plan}

\subsection{External advice}

Should entrepreneurs get external advice to maximize their chances of success? A recent study of advisory committees found that SMEs with such committees are much more successful than those that do not, with a weekly increasing of $18 \%$ on the average sales. The Counselling committees can also provide an increasing in market share, where the growt of the average sales can be three times more important after the adoption of a counselling committee. Our survey comprised two questions aimed at exploring the link among the kind of external counsel companies have received and the performance of their financial resources during the last 3 years. The first question related to the use of official consultative means, like the use of counselling committees or external counsellors, and the second question is related to the informal consultative means, such as networking. The responses to these two questions indicate that the most successful firms are more likely to seek external counsel over the informal and the formal counselling means. The use of a formal mean, however, seems more affect the company successful. Using a scale between 0 and 10, we can conclude that the use of formal means like counselor is about $34 \%$ higher common among companies that perform better than other companies; the use of informal mechanisms such as networking was only $12 \%$ more frequent among the former than among the second. In addition, 20\% upper of the most successful companies answered certainly not having adopted any formal consultative mechanism.

\subsection{Business plan}

What are the company visions made by the entrepreneurs for the next 5 years? It is a simple question, but it is more difficult to answer it and to reach such a goal. The survey results reveal that the success of a business certainly involves the development of a concrete medium-term plan and the use of various measures of performance. Successful firms were significantly more likely than their counterparts, to answer that they think seriously concerning their future plan, developed a strategy, and effectively supervised the evolution of their plan. The survey included different questions about the scheduling as well as performance controlling. The companies were first asked if they made a business plan for the medium-term with detailed objectives. For the most successful companies, more than $70 \%$ firms had such plan, and nearly a third reported a detailed plan for their future growth (see Figure 1). However, for the other group, less than the half of the companies said that they had a sophisticated business plan in the medium term, and only $13 \%$ had just a detailed plan.

Another significant difference also emerges regards to the performance monitoring. Indeed, most companies said that they possess at least one or two performance measures. Nevertheless, around $65 \%$ of the most successful companies answered having at least 3 of these measures, against just over $40 \%$ for other companies. More precisely, for the successful companies, $30 \%$ had at least six measures, and $35 \%$ say that they had none (see Figure 2). 


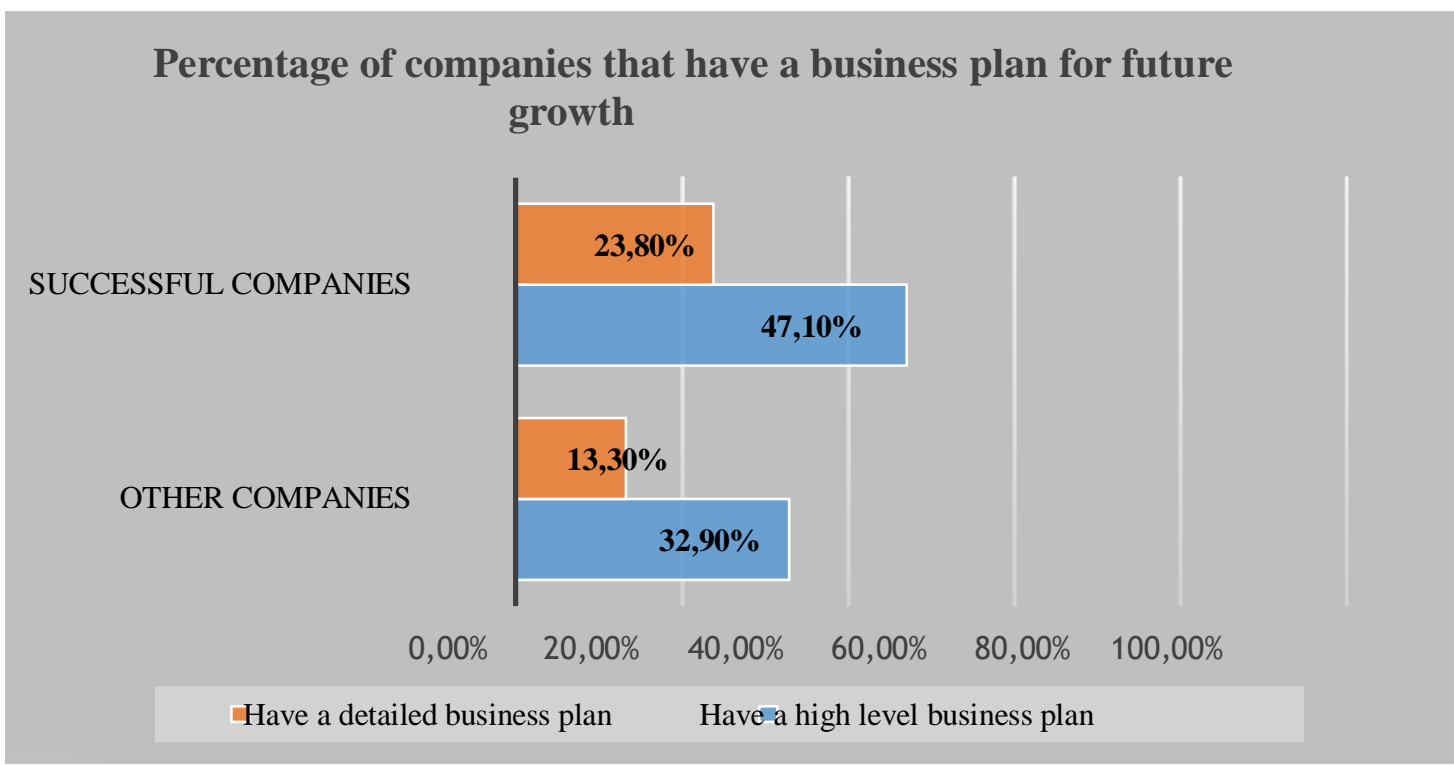

Figure 1. Percentage of companies that have a business plan for future growth

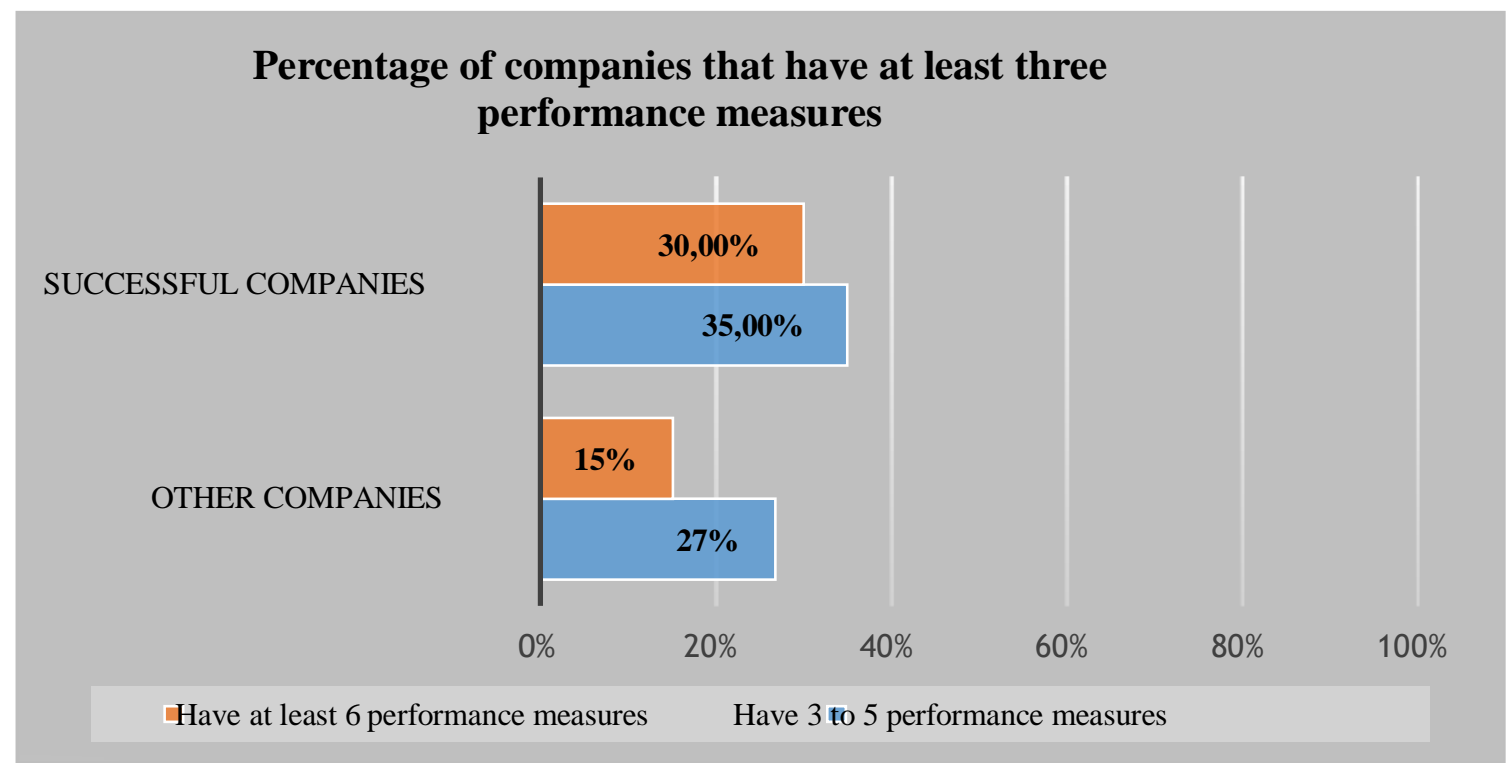

Figure 2. Percentage of companies that have at least three performance measures

\subsection{Relationships with its main suppliers}

It is well known that it is important to connect with customers (following market trends); to reach this goal, it's crucial to build a robust relationship with suppliers. In this framework, the survey results highlight the importance, for a successful business, to maintain links with their competitors, the different educational institutions and their suppliers. The most successful companies have given more importance to all these types of relationships than other companies, but in their view, supplier relationships are the most important (see Figure 3). Indeed, for the successful companies, nearly a third consider that supplier relationships are critical to their success, against less than $20 \%$ for other companies. Likewise, the most successful companies are two times less likely to consider this link with suppliers had no importance to their success. Therefore, since strong client relations are essential, good supplier relations can offer a significant advantage for competition. 


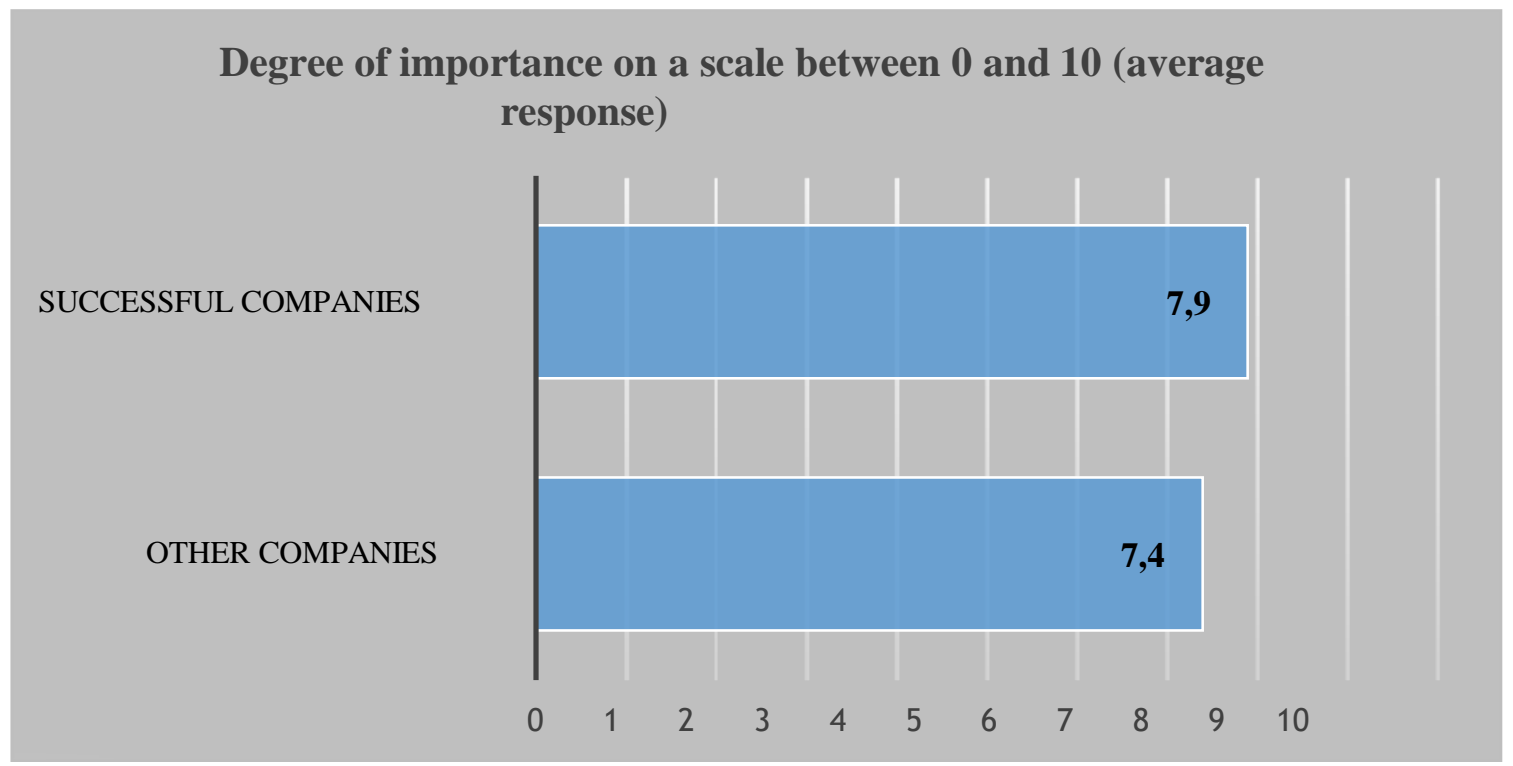

\subsection{Innovation}

Innovation is crucial. In fact, several previous surveys reveals that a varied range of factors related to innovation helps to distinguish the successful companies from the other. The common findings of these researches propose that the innovation has a positive impact on the profits and this relationship remain constant even there is a dramatically change in the global environment of the enterprise. What types of innovation, in particular, have the highest impact on the performance of a company? There are three important findings appeared for all sectors. The most successful companies:

- Commercialize innovative services and products frequently;

- Used novel technologies rapidly;
- A significant number of companies say that innovation practices - process improvement and efficiency of business model adaptation - are critical for their success.

\subsection{Innovative services and products}

About $30 \%$ of the successful companies answered that more than $20 \%$ of their services and products are inexistent before 5 years. However, just one by ten of companies did not offer any new products or services. Contrary, just one by five among all other companies answered that more than $20 \%$ of the offered services and products are inexistent before 5 years, and the rest (around 80\%) offering no new products or service (see Figure 4).

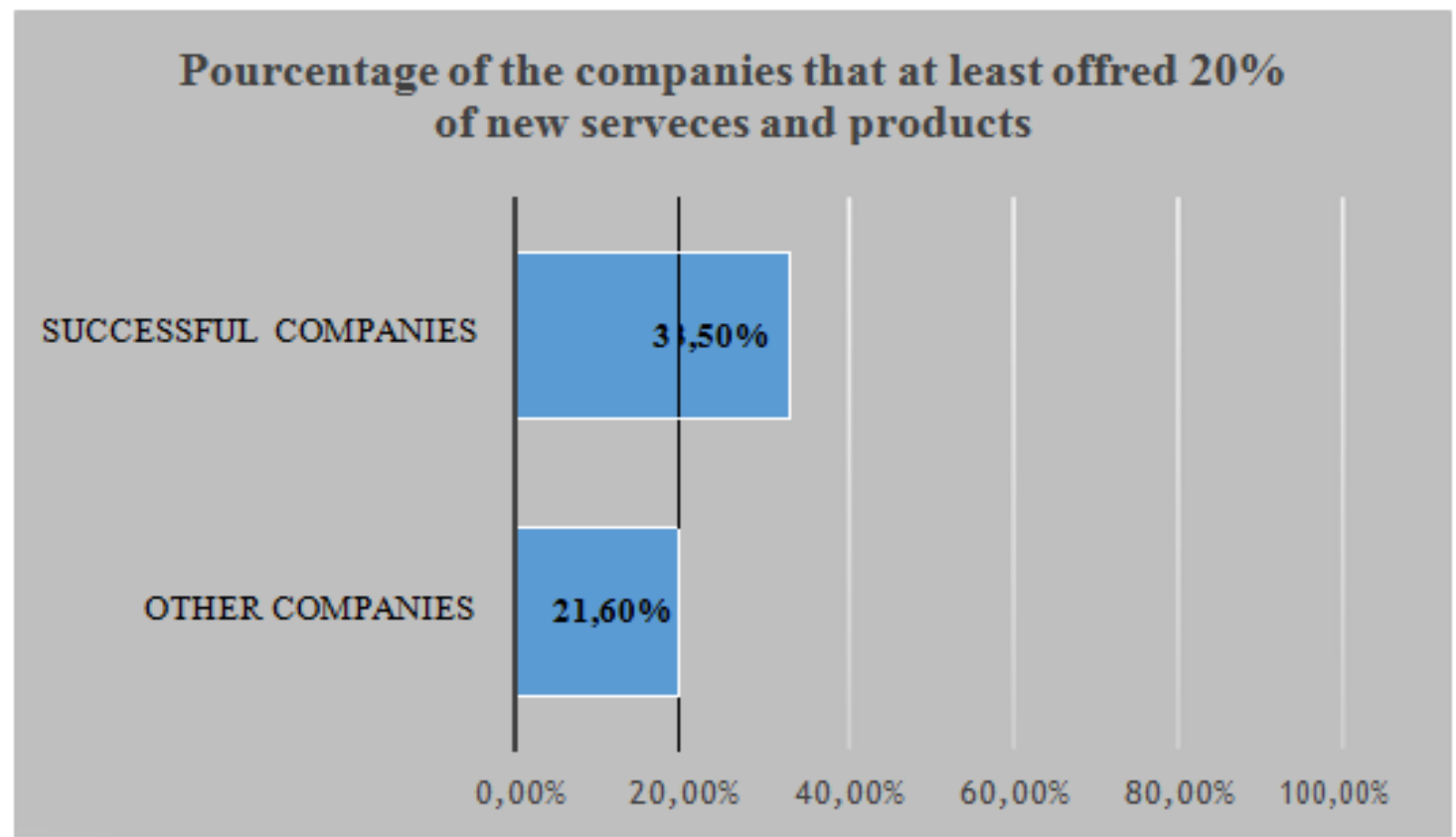

Figure 4. Proportion of companies offering new products and services 


\subsection{New technologies}

For the successful companies, $70 \%$ indicated that they were the first or among the first to adopt new technologies, against only $50 \%$ for the other companies (see Figure 5).

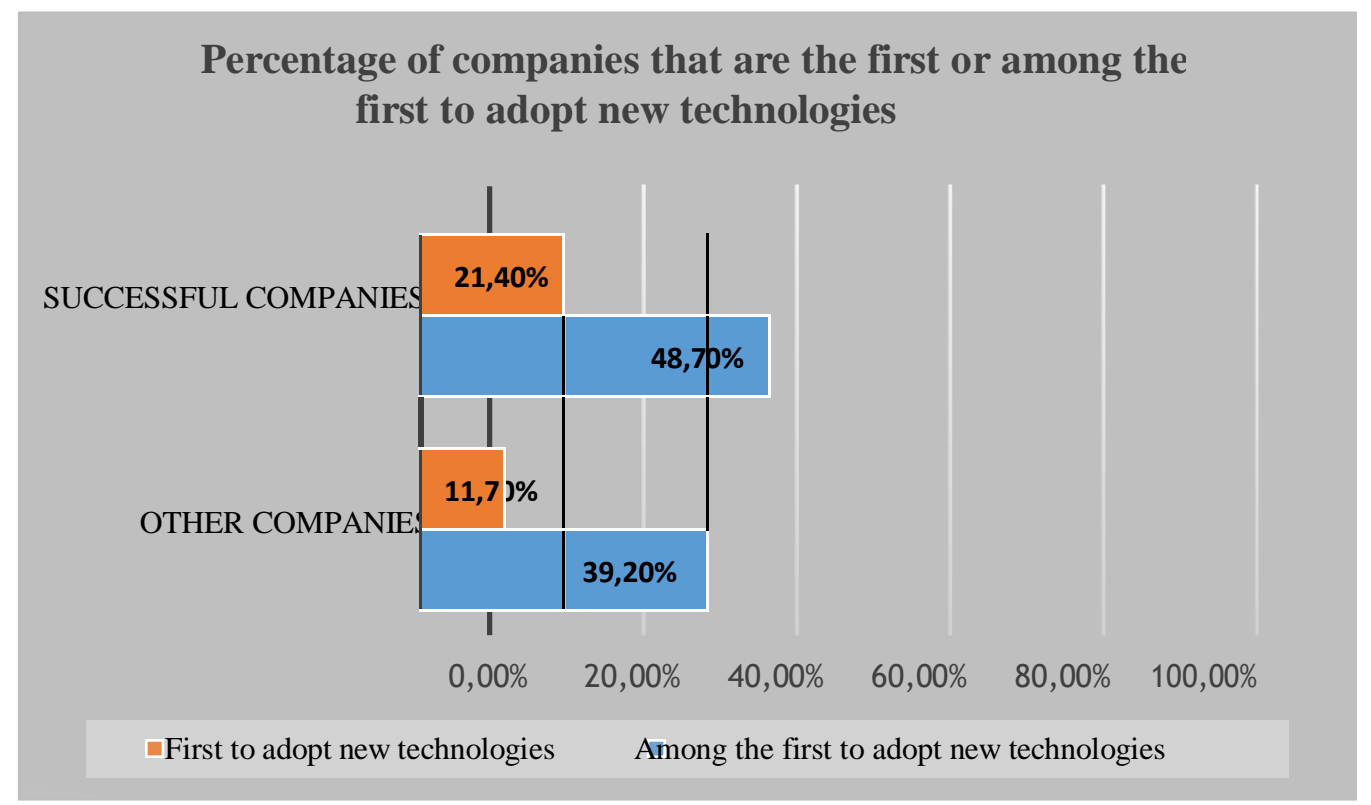

Figure 5. Percentage of companies that are the first or among the first to adopt new technologies

Briefly, the most successful companies have the ability to offer the newest services and products, than the other companies, by using the latest technologies. In addition, they spend more time and resources to find strategies to outperform their competitors.

\section{Human resources}

Recruiting and keeping the qualified employees is a priority for the totality of manager.
More than $60 \%$ of the successful companies were ready to take numerous months to employ just the most promising applicants to fill important positions, against only more than $40 \%$ for the other companies (See Figure 7). More than $30 \%$ of the successful companies take the necessary time to recruit just the best candidates, against just under the quarter for the other firms.

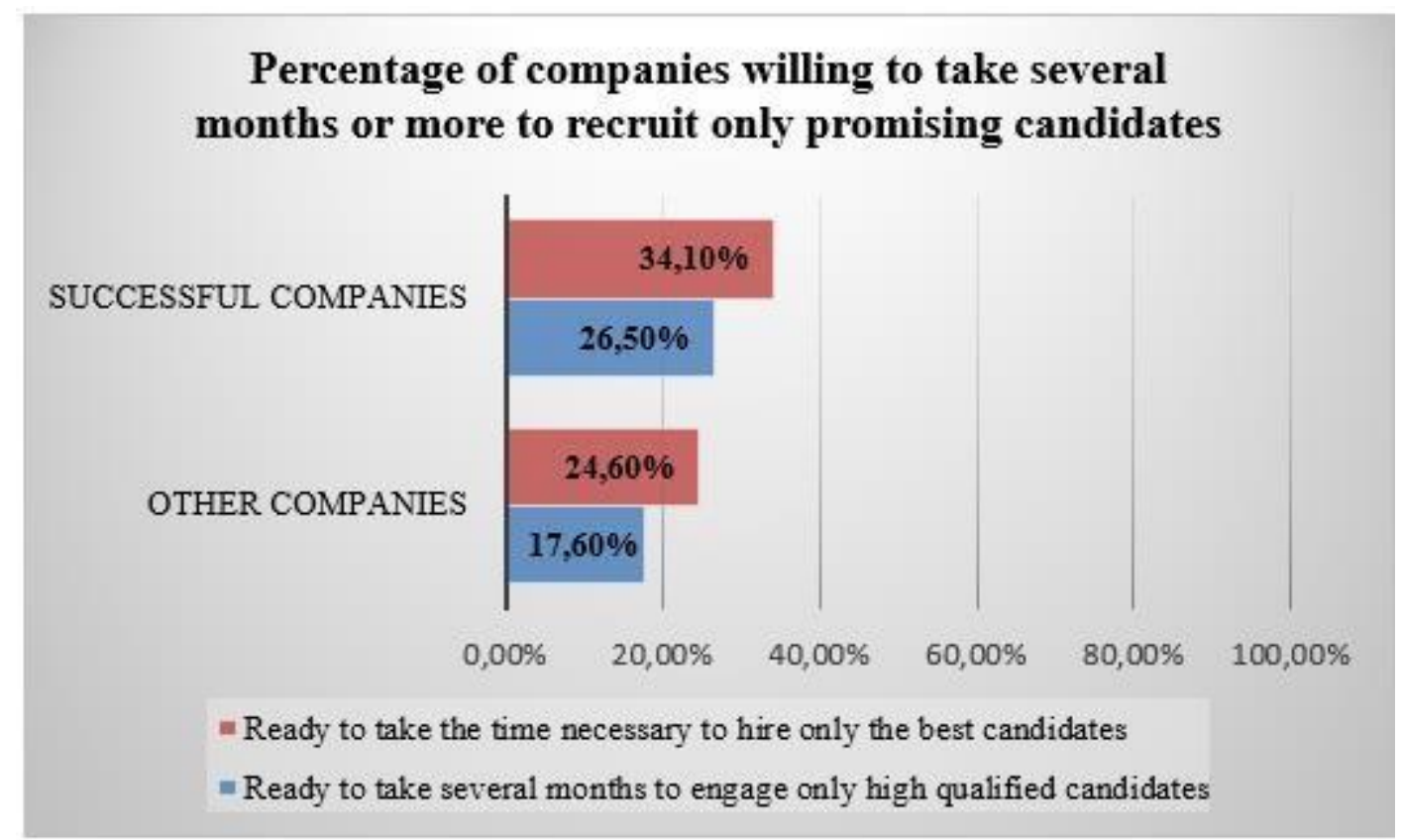

Figure 6. The Percentage of companies were ready to take numerous months to employ just the most promising applicants

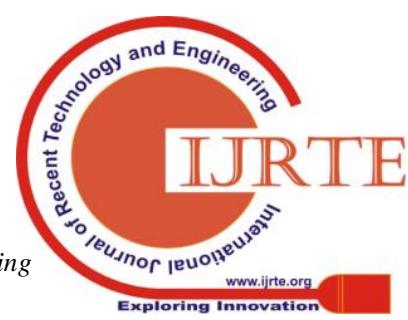




\section{BUSINESS RECOMMENDATIONS}

\subsection{Strategic Vision \& Business Plan}

\subsubsection{Ask for external advice}

Strategies for SMEs envisage the creation of a consulting committee by considering the following points.

- The members of the consulting committee must be free in their decisions. They must feel independent to suggest a different point of view or to discuss the opinions, strategies and decisions of the manager.

- The consulting committee members must come from different business sectors, and ideally, have the complementary knowledge to yours. Most often, it will be preferable for members have expertise in the several domains, such as human resources, marketing, accounting, commercialization, and finance - all essential to running a business. A good knowledge of the business sector is also a valuable asset.

- The committee must organize regular meetings (four times by year at least with a structured manner. Outlines and documents must be organised and directed to the committee member in advance. You must be responsible for the implementation of the agreed goals and report your Business Progress to the committee.

\section{5..1.2. Have robust business plan and follow its progress}

\section{Business Plan}

If you didn't prepared your plan yet, a business plan for a medium term must be prepared and the following elements must be included:

$\checkmark$ A future target and a realistic business plan to accomplish it. In another word; what is your vision and what is your strategy to achieve it?

$\checkmark$ Adopt the SWOT analysis for the next 2 to 5 years. Which mean the strengths, the weaknesses, the opportunities, and threats analysis. Consider the external and the internal environment factors of your company.

$\checkmark$ Put Targets that will help you to determine if your business activity is on the right road. Which results can confirm that your company is attaining its goals?

\section{Different measures of performance}

If you do not measure your performance, how you can evaluate its progress? The measure of the performance measures can allows you to regulate your strategies, identify issues and hence find the appropriate solutions.

$\square$ Specify well what you need to measure and select a point of reference. Think about quality, delivery times, security, the impact of the environment, as well as the satisfaction of your employees and customer.

$\square$ Accumulate data daily. The measures of performance should contain updated data.

$\square$ Provide a simple and clear presentation of the data. Use diagrams, figures or other visual elements to communicate your message effectively to all your partners.

5.. 1.3. Developing strong relationships with your main suppliers

Establish strategic relationships with some suppliers. More precisely, determine which suppliers play a key role in conserving the advantage of your competitive and closely collaborate with them, in order to develop solid relations in your business.

$\square$ Select and sign contract with suppliers who are bests in their domains. This will give you access toward an advanced processes and technologies. An agreement on service levels must address factors such as the description of products and services, the deadlines of payment, information confidentiality, the conformity of regulation, and conflict the conditions related to the end of the contracts.

$\square$ Evaluate the efficacy of your suppliers. Apply evaluation system to measure regularly the effectiveness of your suppliers. Consider factors, like punctual deliveries, costs, flexibility, and quality of service. Address your findings in writing to your suppliers so that they can correct their faults.

\section{1.4. Depend of little diversified customer}

$\square$ Create an official business development plan. Study the historical trends. How your clientele evolved? What is the percentage of your customers whose loss would put your company at risk? After answering these questions, establish clear objectives for the acquisition of new clients and devote resources to the realization of your plan.

$\square$ Think before you customize your products and services. When a large customer asks for a personalized product or service, ask yourself if it is beneficial to accept. If you improve a product that other customers will want to buy, it is probably a good idea for your company.

$\square$ Design products and services for new markets. Create innovative services and products that align with the strategies and capacities of your company. Always remind that the objective is to attract new customers not only to sell to current customers.

\subsubsection{Underestimating the importance of effective} finance management

$\square$ Succeed the basic principles of cash flow management. To realize the cash flow target.

$\square$ Provide detailed financial reports. It is essential to adopt practices to report financial information in detail in order to maintain long-term profit margins. Otherwise, you could focus on non-profitable products, or even those that are sold with a loss.

$\square$ Establish treasury goals (available liquidity). It is important to constitute your existing reserves in financial resources during good periods; which put you in a good financial position and enable you to be financed by other investors and bankers. It's important to remind that these kind of financing can take a long period.

\subsubsection{The preparation of an emergency plan}

$\square$ Identify weaknesses. Consider hypothetical scenarios and identify the situations that might constitute a serious risk to your company, like losing important employees or key customers, a significant increase in raw material costs, the losing of an exceptional supplier or also the disasters of the nature like floods or fires. Set an order of priority.

$\square$ Prepare a plan. You can avoid several problems. Prepare contingency plans that take into account your

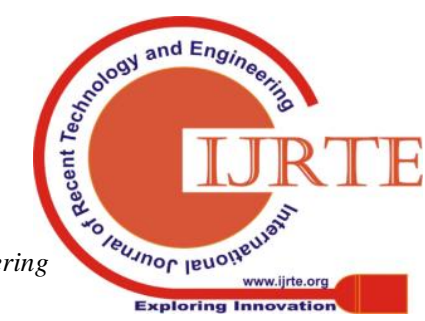


weaknesses.

$\square$ Act quickly. If problems arise, do not delay taking a advice.

$\square$ Communicate regularly with those who care about the success of your business. This includes your main suppliers and those who have an interest in the success of your company, such as banks and other lenders.

$\square$ Do not trust the best scenarios. In the case of companies in our sample that have experienced financial difficulties, excessive optimism has undermined the success of the restructuring.

$\square$ Be candid and clear with your partners. Reorganization frequently requires financial assistance (such as repayment extensions) from partners, including banks. The best way to put all the odds on your side is to be honest and transparent..

\subsection{Innovation}

$\square$ The Innovation strategy needs a good leadership, the disponibility of qualified employees and of course financial resources or capital. You need to be competent in improving the working methods in your enterprise. It's necessary also to think to put some money separately in order to finance your new projects.

$\square$ Use the creativity of your personnel, your partners, your consumers and also of your suppliers, They know your company and your industry very well, and they are often your best source of ideas. Innovating is sometimes simply create new methods or strategies, familiarizing a product to suits new market, and adopting novel techniques in order to attract customers.

$\square$ Do not look too far. Focus on progressive and continuous improvement.

\subsection{Marketing}

\section{The market trends}

$\checkmark$ Satisfy your consumers' needs and regularly listen to them to understand their desires. What are the expectations and real needs of your customers? Who are they? What do they buy? Why are they buying it? It is essential to answer the mentioned questions to develop and offer products or services that will be successful.

$\square$ Inquire about your competitors. Try to understand the brands and the market position of your competitors. Compare their services and products or services to yours, preferably by buying and testing them desires or needs variations, social changes, modern equipment and technologies, new channels for distribution novel capacity could fundamentally modify your market.

\subsubsection{Human resources: Recruit the best employees}

Evaluate the culture of your company. To hire the competent candidates, you must identify the needs of your enterprise. What is the assigned mission? What is the value of this mission? Which mentality do you favour?

$\square$ Do not count the time and effort you spend to find the accurate person.

$\square$ Integrate new employees. In addition to training, you might couples new employees with a former employee that may be their mentor and coach and help them to integrate. radical action, and do not hesitate to search for external

$\checkmark$ Be aware of the market transform factors. Consumer

Provide different rewords and compensation for your employees with an innovative way.

\section{CONCLUSION}

The creation of companies can be an effective solution of the unemployment. Moreover, business development is an essential factor of economic growth. Thus, the development of a country is correlated with its business development. However, business results are not always guaranteed. For this reason, controlling a number of factors related to results is an absolute necessity.

With the aim to identify the factors of success and the factors of failure of companies, a survey was conducted with two panels of Turkish companies, one represents successful companies and the other represents failure companies, the survey was conducted in 2017. The panel of successful companies produced 34 complete surveys and the failure company's panel formed 12, in total 46 surveyed companies. Empirical results highlight the importance of factors related to the Business plan, relationship with suppliers, consumer diversification, financial management, the innovation, the marketing strategy and the human resources. More precisely, we identified five factors that can help the entrepreneurs succeed their companies and five failure factors that they must avoid them;

\section{$>$ Five factors for business success:}

Innovation; create new product and services,

Request to external advice,

$\square$ Make a robust business plan and follow the progress of its execution

$\square$ Employing the competent personnel; money is not enough,

$\checkmark$ Develop Strong Relationships with your main Suppliers.

$>$ Five factors to avoid in order to succeed in business:

$\checkmark$ Depend on an undiversified customers,

$\checkmark$ Underestimating the Importance of an Effective Financial Management,

$\checkmark$ Delay the preparing of an emergency plan,

$\checkmark$ Ignore Market Trends,

$\checkmark$ Delay in asking for help.

The five success factors and five failure factors offer a good reference to different companies. All the entrepreneurs must verify if they implement these key success factors and avoiding these failure factors. The entrepreneurs, who do not possess the resources and the experiences of the successful companies, need support to adopt some strategies especially that the daily challenges associated with the operation of their companies need a lot of attention.

Our findings showed that innovation is the main factor of companies' success. Indeed, the business environment is not always stable hence, the innovation is crucial. Fortunately, all entrepreneurs can implement the success factors and avoid the failure factors that we have identified. However, it takes effort and monitor progress frequently to get results. 


\section{REFERENCES}

1. Achanga, Pius, Esam Shehab, Rajkumar Roy and Geoff Nelder. 2006. "Critical success factors for lean implementation in SMEs". Journal of Manufaeturing Teehnology Management, vo1.17, no4, p460-471

2. Ashley, David, B., Clive S. Lurie and Edward J. Jaselskis. 1987. "Determinants of Construction Project Success". Project Management Journal, vo1.18, no2, p69-80

3. Baker, Bruce N., David C. Murphy and Dalmar Fisher. 1988. Factors affecting project success. In Projeet Management Handbook, p.902. New York: Van Nostrand Reinhold. 2nd edition.

4. [4].Bissonnette, L. 1996. "The key factors of success in the management of tourism projects".Master's thesis. Rimouski: University of Quebec in Rimouski, 87 p.

5. Cooper, Robert G. 2003. "Profitable product innovation: the critical success factors" In The International Handbook on Innovation.

6. De Wit, Anton. 1988. Measurment of project success. International Journal of Project Management, vol.6. no3, p164-170

7. Fryer, Karen 1., Jiju Antony and Alex Douglas. 2007. "Critical success factors of continuous improvement in the public sector: A literature review and sorne key findings".The TQM Magazine, vo1.19, no5, p497-517

8. Mattesich, Paul, Murray-Close Marta and Barbara Monsey. 2001. Collaboration: what makes it work. 2nd Edition. St. Paul, Minnesota: Amherst H. Wilder Foundation, p 82.

9. Morrison, Alison, Paul Lynch and Nick Johns. 2004. "International tourism networks". International Journal of Contemporary Hospitality Management, vo1.16, no3, p198-204

10. Nguyen, Long Duy, Stephen O. Ogunlana and Do Thi Xuan Lan. 2004. "A study on project success factors in large-scale construction projects in Vietnam". Engineering,Construction and Architectural Management, p404-413

11. Pinto, J.K and D.P. Sievin. 1986. "Critical success factors across the life cycle project".International Journal of Project Management, vol. 17, n04, p57-70

12. Préfontaine, Lise, Line Ricard and Hélène Si cotte. 2001. "New models of collaboration for the delivery of public services: State of play". Research report prepared for CEFRIO

13. Préfontaine, Lise, Line Ricard and Hélène Sicotte. 2002. "New models of collaboration for the delivery of public services: findings and challenges". Research report prepared for CEFRIO

14. Reed, Maureen G. 1997. "Power relations and community-based tourism planning".Annals of Tourism Research, vo! .24, n03, p566-591

15. Zwikael, Ofer and Shlomo Globerson. 2006. "From critical success factors to critical success processes". International Journal of Production Research, vo1.44, No. 17, p3433- 3449. 